\title{
Surgical-site infection indices detected by post- discharge surveillance in a medium sized hospital in the city of São Paulo, Brazil
}

\author{
DP Cais*, F Minenelli, K Tonelli, P Rebelo \\ From International Conference on Prevention \& Infection Control (ICPIC 2011) \\ Geneva, Switzerland. 29 June - 2 July 2011
}

\section{Introduction / objectives}

Surgical-site infections (SSI) account for about $24 \%$ of hospital infections. Due to short postoperative staying, SSI diagnosis is eventually made after discharge. SSI rates may be under reported; therefore surveillance after discharge is needed to obtain reliable indices of SSI and to improve quality of care. Aim: To describe the SSI rate assessed after discharge and to compare post-discharge rates to intra hospital rates.

\section{Methods}

This is a retrospective analysis of data collected between September 2009 and December 2010 in a medium sized private hospital in the city of Sao Paulo. Active surveillance after discharge is a governmental requirement and was performed by telephone. We used a standard questionnaire to investigate the occurrence of signs and symptoms of infection: pain, swelling, redness, warmth, fever, presence of secretion and nodules around the incision. Once the SSI was identified, its occurrence was notified and the patient was followed by 60 and 90 days, by telephone.

\section{Results}

From 5,414 surgical patients, 5,213 (96.3\%) agreed to answer the questionnaire. SSI rate was $2.4 \%(129 / 5,414)$ : there were $88(68.2 \%)$ intra hospital SSI and 41 (31.8\%) cases identified post-discharge. No suspected cases of Mycobacterium spp. infection were identified.

\section{Conclusion}

The post-discharge infection rate highlights the importance of a follow up. For institutions that do not have

Infection Control, Hospital Samaritano, São Paulo, Brazil outpatient clinics, post-discharge surveillance is required. Amongst other methods, telephone contact seems to be a reliable strategy since it is possible to assess a large number of patients, although costs and feasibility need to be considered before its implementation.

\section{Disclosure of interest}

None declared.

Published: 29 June 2011

doi:10.1186/1753-6561-5-S6-P193

Cite this article as: Cais et al:: Surgical-site infection indices detected by post-discharge surveillance in a medium sized hospital in the city of São Paulo, Brazil. BMC Proceedings 2011 5(Suppl 6):P193.
Submit your next manuscript to BioMed Central and take full advantage of:

- Convenient online submission

- Thorough peer review

- No space constraints or color figure charges

- Immediate publication on acceptance

- Inclusion in PubMed, CAS, Scopus and Google Scholar

- Research which is freely available for redistribution

\section{() Biomed Central}

\section{Biomed Central}

